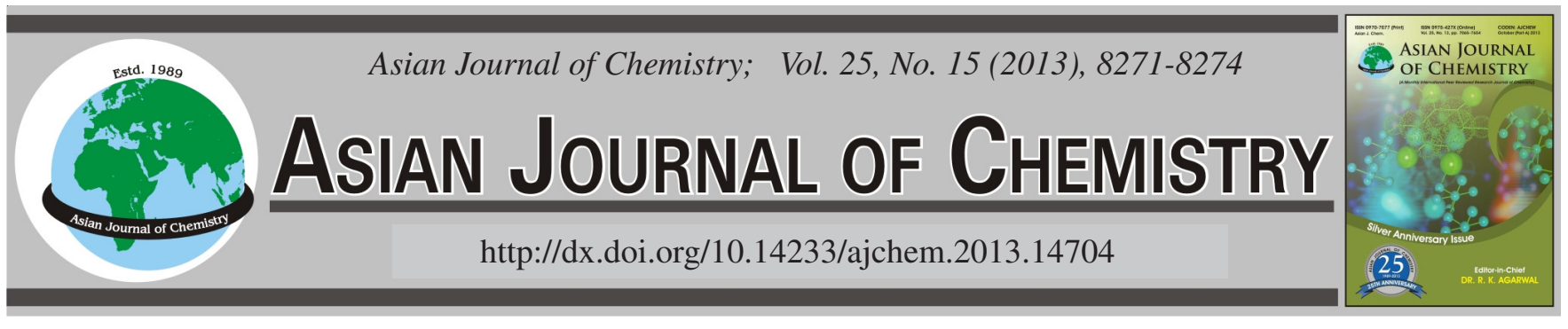

\title{
Volumetric and Viscometric Study of Amino Acids in Aqueous Solution of Maltose at Different Temperatures
}

\author{
PARVINDER KhANUJA ${ }^{1, *}$ and V.R. ChOUREY ${ }^{2}$
}

${ }^{1}$ Department of Chemistry, Shri Neelkantheaahwar Govt. Postgraduate College, Khandwa-450 001, India

${ }^{2}$ Department of Chemistry, Holkar Science College, Indore-452 001, India

*Corresponding author: E-mail: p_khanuja@ rediffmail.com

(Received: 17 October 2012;

Accepted: 16 August 2013)

AJC-13930

\begin{abstract}
Density and viscosity measurements were performed for amino acids in 0.05-0.25 M aqueous maltose at 293.15, 303.15 and 313.15 K. The measured values of density and viscosity were used to estimate some important parameters, such as the partial molal volume, the partial molal volume of transfer, the second derivative of the infinite dilution of the standard partial molal volume with temperature, the viscosity B-coefficients, variation of B with temperature, $\mathrm{dB} / \mathrm{dT}$, the free energy of activation per mole of solvent amino acid in a ternary system. These parameters were interpreted in terms of solute-solute and solute-solvent interactions and structure making/breaking ability of solutes in the given solution.
\end{abstract}

Key Words: Density, Viscosity, Viscosity B coefficient, Free energy activation parameters.

ᄂ - - - - - - - - - - - - - - - - - - - - - - - - -

\section{INTRODUCTION}

Studies on thermodynamic properties have been made on aqueous ternary systems containing carbohydrates and amino acids. It has been reported earlier that mono and disaccharides are structures makers, suggesting hydrogen bonding with $-\mathrm{OH}$ group of sugar and water ${ }^{1-3}$. Hydration shell co-sphere overlap effect depends significantly on the relative position of the $-\mathrm{OH}$ group in the carbohydrate molecules. It would be interesting to examine whether the structure modification of water by these sugars get enhanced or suppress in presence of an ion.

Amino acids, particularly important in biochemistry, are critical to life and have many functions in metabolism one particularly important function is to serve as a building blocks of proteins ${ }^{4,5}$. There are extensive volumetric properties studies of amino acid in mixed aqueous solvents such as sodium sulphate, potassium thiocynate, magnesium chloride and glycerol $^{6-8}$ can act as an effective probes of their confirmation in solutions.

Interaction of amino acids in aqueous maltose solution at different temperature plays an important role to understand biochemical process in living cells.

In this paper, we report density, viscosity and apparent molar volume $\Phi_{\mathrm{v}}$ of $(0.05-0.15 \mathrm{~m})$ amino acids (glycine, alanine) and valine $(0.01-0.04 \mathrm{~m})$ in $(0.05-0.25 \mathrm{~m})$ aqueous maltose solution at $293.15,303.15$ and $313.15 \mathrm{~K}$. We also reported partial molar volume at infinite dilution, transfer volume, partial molar expansibilities, Falkenhagen coefficient A, Jones-Dole coefficient B, free energy parameter of per mole solute and per mole of solvent calculated by experimentally measured density and viscosity.

\section{EXPERIMENTAL}

The maltose and amino acids were used are of analytical grade. Freshly distilled water with specific conductance of $10^{-6} \Omega \mathrm{cm}^{-1}$ was used to preparing solution throughout the experiment. The aqueous solution of maltose was made by weight and molalities were converted in to molarities using the standard expression $^{9}$. The densities of solutions were measured at $293.15,303.15$ and $313.15 \mathrm{k}$ using a single stem pycnometer made of borosil glass. The mass measurement were done on digital electronic balance (Sartorius GC103). Viscosity determines with calibrated $U$ shaped Ostwald viscometer ${ }^{9,10}$ with sufficiently long reflux time more than 2 min to avoid kinetic energy correction. An average of triplet measurement was taken in to account. Temperature was controlled by thermostatic water-bath with $\pm 0.1^{\circ} \mathrm{C}$ accuracy.

\section{RESULTS AND DISCUSSION}

The experimental densities, viscosities and apparent molar volume of amino acids in aqueous maltose were measured at different temperatures. The apparent molar volume, $\Phi_{\mathrm{v}}$ of the amino acids was calculated using the following equation ${ }^{11}$ : 


$$
\Phi v=\frac{M}{d_{0}}-\frac{1000\left(d-d_{0}\right)}{d_{0} \mathrm{c}}
$$

where $d_{0}$ and $d$ are the densities of solvent and solution, respectively; $\mathrm{c}$ is the molar concentration in gram/liter and $\mathrm{M}$ is molecular weight of solute. For each system $\Phi_{\mathrm{v}}$ versus $\sqrt{\mathrm{c}}$ plots were found to be linear thus the data are filled to Masson ${ }^{12}$ equation and calculate limiting partial molar volume and experimental slope by least square method.

$$
\Phi_{\mathrm{v}}=\Phi_{\mathrm{v}_{0}}+\mathrm{S}_{\mathrm{v}} \sqrt{\mathrm{c}}
$$

where $S_{v}$ is the experimental slope or volumetric pair wise interaction coefficient provides information regarding solutesolute interaction. While $\Phi_{\mathrm{v}_{0}}$ provides information regarding solute-maltose water interaction. The values of $\Phi_{v_{0}}$ and $S_{v}$ for the amino acids in aqueous maltose solution at different temperatures are presented in Tables 1 and 2 .

The volume of transfer of amino acids from water to aqueous maltose solution was calculated by using relation at different temperatures and summarized in Table-3.

$\Delta \Phi_{\mathrm{v}_{0 \mathrm{tr}}}=\Phi_{\mathrm{v}_{0}}$ (amino acids in aq. maltose) $-\Phi_{\mathrm{v}_{0}}$ (amino acids in water)

It can be found that the negative $\Delta \Phi_{\mathrm{v}_{0 \text { tr }}}$ values are decreasing continuously with increasing maltose concentration and decrease with increasing temperature. Negative $\Delta \Phi_{\mathrm{v}_{0 t r}}$ has also been reported oxalic acid aqueous glucose $\mathrm{e}^{13}$ and glycine in silver sulphate ${ }^{14}$. In case of alanine and valine it can be found that the positive $\Delta \Phi_{\mathrm{v}_{0 \text { tr }}}$ values are decreasing continuously with decreasing maltose concentration and negative value obtained with increasing temperature. Positive $\Delta \Phi_{\mathrm{v}_{0 \text { tr }}}$ has also been reported $\alpha$-amino acid in aqueous glycerol ${ }^{9}$ and tartazine ${ }^{15}$ solution and amino acid in sodium carprylate solution ${ }^{16}$. The partial molar volume of transfer of amino acids from water to aqueous maltose solutions can be simplified by the co-sphere overlap model, as further developed by Friedman and $\mathrm{Krishnan}^{17}$. A property of water molecules in the hydration co sphere of the solute depends upon the nature of solute species. The types of interaction between amino acids and maltose can be classified as follows.

Hydrophilic-ionic interaction between the -OH group of the maltose and the zwitter ionic centers of the amino acids (glycine/alanine/valine). Hydrophilic-hydrophilic interaction between the $-\mathrm{OH}$ group of the maltose and the $-\mathrm{NH}_{2}$ group of amino acids mediated through hydrogen bonding. Hydrophobic-hydrophobic interaction; between the non polar sides group of the maltose and the non polar group of the aminoacid. Hydrophobic-hydrophilic interaction, between the $-\mathrm{OH}$ group of the maltose molecules and the non-polar group of amino acids.

The interactions of type (1) and (2) contribute positive transfer volume, while type (3) and (4) contribute negatively. The introduction of a $\mathrm{CH}_{3}$ group in alanine and $\mathrm{CH}\left(\mathrm{CH}_{3}\right)_{2}$ group in valine provides additional tendency of hydrophilichydrophobic as well as hydrophobic-hydrophobic.

The temperature dependence of limiting apparent molar volume, $\Phi_{\mathrm{v}_{0}}$ for amino acids in aqueous maltose solution can be represented by following expression ${ }^{13}$.

TABLE-1

PARTIAL MOLAR VOLUME AT INFINITE DILUTION $\Phi \mathrm{v}_{0}\left(\mathrm{~cm}^{3} \mathrm{~mol}^{-1}\right)$ AMINO ACIDS IN AQUEOUS MALTOSE SOLUTION AT DIFFERENT TEMPERATURE (293.15, 303.15 AND 313.15 K)

\begin{tabular}{cccc|ccc|ccc}
\hline \multirow{2}{*}{ Conc. } & \multicolumn{3}{c|}{ Glycine } & \multicolumn{3}{c|}{ L-Alanine } & \multicolumn{3}{c}{ Valine } \\
\cline { 2 - 10 }$y$ & $293.15 \mathrm{~K}$ & $303.15 \mathrm{~K}$ & $313.15 \mathrm{~K}$ & $293.15 \mathrm{~K}$ & $303.15 \mathrm{~K}$ & $313.15 \mathrm{~K}$ & $293.15 \mathrm{~K}$ & $303.15 \mathrm{~K}$ & $313.15 \mathrm{~K}$ \\
\hline $0.25 \mathrm{M}$ & 42.25 & 43.07 & 43.98 & 59.54 & 60.71 & 61.35 & 91.87 & 92.39 & 92.83 \\
$0.20 \mathrm{M}$ & 42.216 & 43.04 & 43.94 & 59.47 & 60.63 & 61.22 & 91.78 & 92.3 & 92.77 \\
$0.15 \mathrm{M}$ & 42.18 & 43.00 & 43.87 & 59.39 & 60.52 & 61.13 & 91.7 & 92.22 & 92.69 \\
$0.10 \mathrm{M}$ & 42.11 & 42.95 & 43.83 & 59.36 & 60.48 & 61.10 & 91.65 & 92.16 & 92.61 \\
$0.05 \mathrm{M}$ & 42.06 & 42.91 & 43.8 & 59.30 & 60.39 & 61.06 & 91.58 & 92.1 & 92.57 \\
\hline
\end{tabular}

\begin{tabular}{|c|c|c|c|c|c|c|c|c|c|}
\hline \multirow{3}{*}{ Conc. } & \multicolumn{8}{|c|}{$\begin{array}{l}\text { TABLE-2 } \\
\text { EXPERIMENTAL SLOPE Sv }\left(\mathrm{cm}^{3} \mathrm{~L}^{1 / 2} \mathrm{~mol}^{-3 / 2}\right) \text { OF AMINO ACIDS IN AQUEOUS MALTOSE } \\
\text { SOLUTION AT DIFFERENT TEMPERATURE }(293.15,303.15 \text { AND } 313.15 \mathrm{~K})\end{array}$} & \\
\hline & \multicolumn{3}{|c|}{ Glycine } & \multicolumn{3}{|c|}{ L-Alanine } & \multicolumn{3}{|c|}{ Valine } \\
\hline & $293.15 \mathrm{~K}$ & $303.15 \mathrm{~K}$ & $313.15 \mathrm{~K}$ & $293.15 \mathrm{~K}$ & $303.15 \mathrm{~K}$ & $313.15 \mathrm{~K}$ & $293.15 \mathrm{~K}$ & $303.15 \mathrm{~K}$ & $313.15 \mathrm{~K}$ \\
\hline $0.25 \mathrm{M}$ & 1.43 & 1.37 & 0.992 & -0.816 & -0.859 & -0.782 & -1.81 & -1.56 & -2.73 \\
\hline $0.20 \mathrm{M}$ & 1.30 & 1.20 & 0.815 & -0.628 & -0.99 & -0.529 & -2.28 & -1.53 & -2.67 \\
\hline $0.15 \mathrm{M}$ & 1.04 & 1.26 & 0.938 & -0.593 & -0.666 & -0.475 & -2.11 & -1.19 & -2.37 \\
\hline $0.10 \mathrm{M}$ & 1.03 & 1.16 & 0.966 & -0.741 & -0.788 & -0.549 & -2.3 & -1.125 & -2.41 \\
\hline $0.05 \mathrm{M}$ & 0.817 & 1.12 & 0.782 & -0.697 & -0.566 & -0.548 & -2.03 & -1.15 & -2.45 \\
\hline
\end{tabular}

TABLE-2

TABLE-3

$\Delta \Phi \mathrm{V}_{0 \mathrm{tr}}\left(\mathrm{cm}^{3} \mathrm{~mol}^{-1}\right)$ OF AMINO ACIDS IN AQUEOUS MALTOSE SOLUTION

\begin{tabular}{|c|c|c|c|c|c|c|c|c|c|}
\hline \multirow{2}{*}{ Conc. } & \multicolumn{3}{|c|}{ Glycine } & \multicolumn{3}{|c|}{ L-Alanine } & \multicolumn{3}{|c|}{ Valine } \\
\hline & $293.15 \mathrm{~K}$ & $303.15 \mathrm{~K}$ & $313.15 \mathrm{~K}$ & $293.15 \mathrm{~K}$ & $303.15 \mathrm{~K}$ & $313.15 \mathrm{~K}$ & $293.15 \mathrm{~K}$ & $303.15 \mathrm{~K}$ & $313.15 \mathrm{~K}$ \\
\hline $0.25 \mathrm{M}$ & -0.53 & -0.21 & -0.02 & 0.45 & -0.01 & 0.15 & 0.97 & 0.345 & 0.18 \\
\hline $0.20 \mathrm{M}$ & -0.56 & -0.24 & -0.051 & 0.38 & -0.09 & 0.02 & 0.88 & 0.255 & 0.12 \\
\hline $0.15 \mathrm{M}$ & -0.60 & -0.28 & -0.13 & 0.3 & -0.2 & -0.07 & 0.8 & 0.175 & 0.04 \\
\hline $0.10 \mathrm{M}$ & -0.67 & -0.33 & -0.17 & 0.27 & -0.24 & -0.1 & 0.75 & 0.115 & -0.04 \\
\hline $0.05 \mathrm{M}$ & -0.72 & -0.37 & -0.21 & 0.21 & -0.33 & -0.14 & 0.68 & 0.055 & -0.08 \\
\hline
\end{tabular}
AT DIFFERENT TEMPERATURE (293.15, 303.15 AND 313.15 K) 


$$
\Phi_{\mathrm{v}_{0}}=\mathrm{a}_{0}+\mathrm{a}_{1} \mathrm{~T}+\mathrm{a}_{2} \mathrm{~T}^{2}
$$

The partial molar expansibilities of amino acids in aqueous maltose were calculated and recorded in Table-5.

$$
\Phi_{\mathrm{E}_{0}}=\left(\partial \Phi_{\mathrm{v}_{0}} / \partial \mathrm{T}\right)_{\mathrm{p}}=\mathrm{a}_{1}+2 \mathrm{a}_{2} \mathrm{~T}
$$

The structure making and breaking capacity of amino acids in aqueous maltose may be interpreted with the help of Hepler's ${ }^{18}$ reasoning i.e., on the basis of sign of giving expression.

$$
\left(\frac{\partial \Phi_{\mathrm{E}_{0}}}{\partial_{\mathrm{T}}}\right)_{\mathrm{p}}=\left(\frac{\partial^{2} \Phi_{\mathrm{v}_{0}}}{\partial \mathrm{T}^{2}}\right)_{\mathrm{p}}=-\mathrm{a}_{2}
$$

On the basis of this expression, it has been assumed that structure making solute have positive and structure breaking solute has negative value, was determined.

Time of flow was determined for amino acids in aqueous maltose at chosen concentration and temperature. The viscosity were determined from the formula.

$$
\frac{\eta}{\eta_{0}}=\frac{\mathrm{td}}{\mathrm{t}_{0} \mathrm{~d}_{0}}
$$

Viscosity data has been analyzed with the help of Jonesdole ${ }^{19}$ equation from the linear plots of $\left[\left(\eta / \eta_{0}\right)^{-1}\right] / \mathrm{c}^{1 / 2}$ versus $\mathrm{c}^{1 / 2}$ by least square method. The viscosity $\mathrm{A}$ and $\mathrm{B}$ coefficients were obtained from the intercepts and slopes and are given in Table-4.

$$
\frac{\eta}{\eta_{0}}=\eta \mathrm{r}=1+\mathrm{Ac}^{1 / 2}+\mathrm{BC}
$$

The values of $(\mathrm{dB} / \mathrm{dT})$ were calculated from the slope of the curve obtained by plotting $\mathrm{B}$-coefficient ${ }^{20}$ value against temperatures and recorded in Table- 6 .

The free energy of activation per mole of solute and solvent of viscous flow ${ }^{21,22}$ was also evaluated.

It is found that value of $\Phi_{\mathrm{v}_{0}}$ for all amino acids is positive and increase with increasing concentration of maltose and increasing trend suggests solute-solvent interaction increases. Similar conclusion has been reported for amino acid in aqueous
$\mathrm{NH}_{4} \mathrm{Cl}^{23}, \mathrm{NaCl}-\mathrm{KCl}^{24}$, methanoic acid ${ }^{25}$ and glycerol ${ }^{8}$ solution as $\Phi_{\mathrm{v}_{0}}$ increases with rise in temperature. It can be observed that $\Phi_{\mathrm{v}_{0}}$ increase with temperature its show that reduction of electrostriction occurs. It is found that value of $S_{v}$ is positive for glycine and negative for alanine and valine in aqueous maltose solution. The $\Phi_{\mathrm{v}_{0}}$ value is greater than $\mathrm{S}_{\mathrm{v}}$ for all concentration range suggests that solute- solvent interaction predominant over solute-solute interaction.

It is found that value of $\Phi_{\mathrm{v}_{0 t r}}$ is negative for glycine and positive and negative for alanine and valine in aqueous maltose solution. The positive $\Phi_{\mathrm{vtr}}$ value obtained due to reduction ${ }^{26}$ or loosening of electrostricted hydration zone around zwitter ionic ends and due to destruction of hydrophobic hydration around the carbon skeleton in the presence of co solvents. The electrostriction of the neighboring water due to these charged centers will be diminish in the presence of maltose this will lead to decrease in reduction of shrinkage. The electrostriction diminish on addition of maltose due to shielding of zwitter ionic group by maltose the structure of maltose reveal several possible sites at which can interact with zwitter ionic of amino acids .As a result amino acid are unable to exert their maximum electrostriction effect in presence of maltose. It brings about increase in volume of the solvent thereby decreasing the strong interaction between carbohydrate and water. This will lead to positive volume transfer. This is consistent with amino acid in glycerol $^{27}$, ammonium chloride ${ }^{23}$ solutions. In this cases, hydrophilic interactions are dominating at higher concentration, while hydrophobic interactions are dominating at lower concentration. Both negative and positive transfer volume has been reported by $\mathrm{Pal}$ and Chauhan ${ }^{28} \mathrm{~L}$-alanine in higher concentration of maltose solution. In case of alanine and valine positive $\Phi_{\text {vtr }}$ decrease with decreasing concentration and increasing temperature suggests that in this electrostriction first decrease than increase with increasing temperature that reveal elerostriction increase at high temperature.

\begin{tabular}{|c|c|c|c|c|c|c|c|c|c|}
\hline \multirow{3}{*}{ Conc. } & \multicolumn{8}{|c|}{$\begin{array}{l}\text { TABLE-4 } \\
\text { VISCOSITY B COEFFICIENT }\left(\mathrm{m}^{3} \mathrm{~mol}^{-1}\right) \text { OF AMINO ACIDS IN AQUEOUS MALTOSE } \\
\text { SOLUTION AT DIFFERENT TEMPERATURE (293.15,303.15 AND } 313.15 \mathrm{~K})\end{array}$} & \\
\hline & \multicolumn{3}{|c|}{ Glycine } & \multicolumn{3}{|c|}{ L-Alanine } & \multicolumn{3}{|c|}{ Valine } \\
\hline & $293.15 \mathrm{~K}$ & $303.15 \mathrm{~K}$ & $313.15 \mathrm{~K}$ & $293.15 \mathrm{~K}$ & $303.15 \mathrm{~K}$ & $313.15 \mathrm{~K}$ & $293.15 \mathrm{~K}$ & $303.15 \mathrm{~K}$ & $313.15 \mathrm{~K}$ \\
\hline $0.25 \mathrm{M}$ & 0.1445 & 0.1244 & 0.1151 & 0.141 & 0.1501 & 0.177 & 0.429 & 0.465 & 0.565 \\
\hline $0.20 \mathrm{M}$ & 0.1468 & 0.1234 & 0.1162 & 0.133 & 0.1446 & 0.155 & 0.391 & 0.3999 & 0.478 \\
\hline $0.15 \mathrm{M}$ & 0.1477 & 0.1237 & 0.1172 & 0.131 & 0.14 & 0.147 & 0.328 & 0.342 & 0.384 \\
\hline $0.10 \mathrm{M}$ & 0.148 & 0.1239 & 0.113 & 0.119 & 0.124 & 0.135 & 0.275 & 0.283 & 0.306 \\
\hline $0.05 \mathrm{M}$ & 0.1488 & 0.116 & 0.109 & 0.103 & 0.108 & 0.111 & 0.221 & 0.222 & 0.242 \\
\hline
\end{tabular}

In case of glycine negative $\Phi_{\mathrm{vtr}}$ decrease with increasing

\begin{tabular}{|c|c|c|c|c|c|c|c|c|c|}
\hline \multirow{3}{*}{ Conc. } & \multicolumn{8}{|c|}{ TABLE-5 } & \\
\hline & \multicolumn{3}{|c|}{ Glycine } & \multicolumn{3}{|c|}{ L-Alanine } & \multicolumn{3}{|c|}{ Valine } \\
\hline & $293.15 \mathrm{~K}$ & $303.15 \mathrm{~K}$ & $313.15 \mathrm{~K}$ & $293.15 \mathrm{~K}$ & $303.15 \mathrm{~K}$ & $313.15 \mathrm{~K}$ & $293.15 \mathrm{~K}$ & $303.15 \mathrm{~K}$ & $313.15 \mathrm{~K}$ \\
\hline $0.25 \mathrm{M}$ & 0.0775 & 0.0865 & 0.0955 & 0.1440 & 0.0900 & 0.0360 & 0.056 & 0.048 & 0.040 \\
\hline $0.20 \mathrm{M}$ & 0.0781 & 0.0866 & 0.0951 & 0.1410 & 0.0910 & 0.0410 & 0.055 & 0.050 & 0.045 \\
\hline $0.15 \mathrm{M}$ & 0.0795 & 0.0845 & 0.0895 & 0.1386 & 0.0866 & 0.0346 & 0.054 & 0.049 & 0.044 \\
\hline $0.10 \mathrm{M}$ & 0.082 & 0.086 & 0.09 & 0.1384 & 0.0874 & 0.0364 & 0.054 & 0.048 & 0.042 \\
\hline $0.05 \mathrm{M}$ & 0.0825 & 0.0865 & 0.0905 & 0.1299 & 0.0879 & 0.0459 & 0.054 & 0.049 & 0.044 \\
\hline
\end{tabular}
concentration and temperature suggests that in this electrostriction first increase than decrease with increasing temperature that reveal elerostriction decrease at high temperature. 
TABLE-6

dB/dT COEFFICIENT OF AMINO ACIDS IN AQUEOUS

MALTOSE SOLUTION AT DIFFERENT TEMPERATURE (293.15, 303.15 AND 313.15 K)

\begin{tabular}{cccc} 
Conc. & Glycine & L-Alanine & L-Valine \\
0.25 & -0.00147 & 0.00184 & 0.0068 \\
0.20 & -0.00153 & 0.0011 & 0.0043 \\
0.15 & -0.00153 & 0.0008 & .00278 \\
0.10 & -0.00175 & .00079 & 0.0155 \\
0.05 & -0.00199 & 0.0004 & 0.0105 \\
\hline
\end{tabular}

Both negative and positive transfer volume has been reported by Pal and $\mathrm{Kumar}^{29}$ glycine in 2, 4 and $6 \%$ maltose solution. The increasing in positive $\Phi_{\mathrm{vtr}}$ in valine in comparison to alanine suggests hydrophilic-hydrophobic interaction is dominant over hydrophobic-hydrophobic interaction. In case of valine less negative $\Phi_{\mathrm{vtr}}$ with increasing concentration and increase with temperature suggests that will lead to increase in reduction of shrinkage on rise with temperature. In case of glycine electrostriction first increase than decrease with increasing temperature, that shows that elerostriction decrease at high temperature.

The limiting apparent molar expansibilities for glycine in aqueous maltose obtained at different temperature showed that FE0- value decrease with concentration and increase with temperature. This positive increase in $\Phi_{\mathrm{E}_{0}}$ may be indicating presence of caging effect ${ }^{30}$. In other words, solute occupies the interstitial space in the solvent, water resulting in hydrophobic structure making character ${ }^{31}$. The positive value of $\left(\partial^{2} \Phi_{v_{0}} / \partial T^{2}\right)_{p}$ has been found to be suggesting structure making nature. Opposite behaviour negative value of $\left(\partial \Phi_{v_{0}} / \partial T^{2}\right)_{p}$ has been found in the case of alanine and valine.

It is found that value of A coefficients are negative for all amino acids in aqueous maltose at the investigated temperatures. These results indicates the presence of weak solutesolute interaction.

The value of B-coefficient for glycine is positive and decreases with rise in temperature whereas for alanine and valine it increases with increase in temperature. It may be concluded glycine as structure-maker and alanine and valine as structure-breaker in aqueous maltose solutions. That further, supporting earlier conclusion drawn from $\Phi_{\mathrm{v}_{0}}$ and $\mathrm{S}_{\mathrm{v}}$. Negative $(\mathrm{dB} / \mathrm{dT})$ value reveals structure making capacity of glycine in sucrose increase with increasing concentration. Positive $(\mathrm{dB} /$ dT) value reveal structure breaking capacity of alanine and valine in maltose increase with increasing concentration. These are in identical agreement with the conclusion drawn from Hepler equation as discussed earlier. Such the values of coefficient A and B supports the behaviours of $\Phi_{\mathrm{v}_{0}}$ and $S_{\mathrm{v}}$ and $\Phi_{\mathrm{v}_{0 \mathrm{tr}}}$ which all suggest solute solvent interaction predominant over solute- solute interaction.

Positive value of $\Delta G$ increases with the increase in solute concentration and decreases with the rise of temperature. This behaviour of $\Delta \mathrm{G}$ suggests that positive work is required to create holes ${ }^{32}$ for viscous flow and to weaken the solute-solvent and solvent-solvent interactions at higher temperature due to thermal agitation. Hydrophilic-hydrophobic interactions between the -OH group of the glucose and non-polar groups of amino acids, which lead to a positive contribution to $\Delta \mathrm{H}^{33}$. The positive value of $\Delta \mathrm{H}$ increases with the increase of solute composition. This indicates that to overcome the energy barrier more positive work has to be done. Thus the viscous flow is not favoured for all the glucose molecules in solution systems. This may be due to the fact that the ground state of the binary and ternary systems is more organized than the transition states.

\section{ACKNOWLEDGEMENTS}

The authors are thankful to The Principal, Holkar Science College, Indore, India for the facilities provided. One of the authors (P.K.) is also thankful to U.G.C., New Delhi for the teacher research fellowship.

\section{REFERENCES}

1. S. Galema and A. Hoiland, J. Phys. Chem., 95, 5321 (1991).

2. P.K. Banipal, T.S. Banipal, B.S. Lark and J.C. Ahluwalia, J. Chem. Soc. Faraday Trans., 93, 81 (1997).

3. P.K. Banipal, T.S. Banipal, B.S. Lark and J.C. Ahluwalia, J. Chem. Thermodyn., 32, 1409 (2000)

4. D.P. Kharakoz, J. Phys. Chem., 95, 5634 (1991).

5. D.P. Kharakoz, Biophys. Chem., 34, 115 (1989).

6. D. Lan, L. Liu, L. Dong, W. Li, Q. Li and L. Yan, Asian J. Chem., 25, 2709 (2013).

7. A. Pal and S. Kumar, Indian J. Chem. Sci., 117, 267 (2005).

8. A. Ali, S. Khan and F. Nabi, J. Serb Chem. Soc., 72, 495 (2007).

9. J.A. Kitchner, Findlay, Practical Physical Chemistry, Longman, London, edn. 8, p. 70 (1954).

10. C. Garland, J. Nibler and D. Shoemaker, Experiment In Physical Chemistry, McGraw Hill, New York, p. 131 (1967).

11. B.B. Panda, G. Dixit and B. Behera, Bull. Chem. Soc Japan, 69, 301 (1996).

12. D.O. Masson, Philos. Mag., 8, 218 (1929).

13. R. Gupta and M. Singh, J. Indian Chem. Soc., 85, 176 (2008).

14. B. Sinha, P.K. Roy and M.N. Roy, Acta Chim. Slov., 57, 651 (2010).

15. A. Ali, R. Patel and S. Tasneem, Polish J. Chem., 83, 1353 (2009).

16. J.J. Wang, Z.N. Yan and J.S. Lu, J. Chem. Thermodyn., 36, 281 (2004).

17. H.L. Friedman and Krishnan, J. Sol. Chem., 2, 37 (1973).

18. L. Hepler, Can. J. Chem., 47, 4613 (1969).

19. G. Jones and M. Dole, J. Am. Chem. Soc., 51, 2950 (1929).

20. H. Jenkins and Y. Marcus, Chem. Rev., 95, 2695 (1995).

21. D. Feakins, F.M. Canning, W.E. Waghorne and K.G. Lawrence, J. Chem. Soc. Faraday Trans., 89, 3381 (1993).

22. S. Glasstone, K.J. Laidler and H. Eyring, The Theory of Rate Processes, McGraw-Hill, New York (1941).

23. M. Natrajan, R. Wadi and H. Gaur, J. Chem. Eng. Data, 35, 87 (1990).

24. T. Ogawa, K. Mizutani and M. Yasuda, Bull. Chem. Soc. (Japan), 57, 2064 (1984).

25. M.N. Roy, D. Ekka and R. Dewan, Acta Chim. Slov., 58, 792 (2010).

26. I.N. Basumallick and R. Mohanty, Indian J. Chem., 29A, 647 (1990).

27. T.S. Banipal, G. Singh, B.S. Lark, J. Solut. Chem., 30, 7 (2001).

28. A. Pal and N. Chauhan, J. Indian Chem. Soc., 48A, 1069 (2009).

29. A. Pal and S. Kumar, J. Indian Chem. Soc., 79, 866 (2002).

30. F.J. Millero, In ed: R.A.Horne, Structure and Transport Process in Water and Aqueous Solution, Wiley Interscience, New York (1971).

31. M.S.I. Lampreia and J.M.S.T. Neves, J. Chem. Soc. Faraday Trans., 93, 2277 (1997).

32. P. Dey, M.A. Motin and E.M. Huque, Monatsh. Chem., 134, 797 (2003).

33. S. Li, X. Hu, R. Lin and H. Zong, Thermochim. Acta, 342, 1 (1999). 